\title{
Perceived Organizational Support and Organizational Identification: Joint Moderating Effects of Employee Exchange Ideology and Employee Investment
}

\begin{abstract}
Organizational identification (OID) can be developed out of social exchange practices within an organizational setting. Drawing on social exchange theory, we propose that the effect of perceived organizational support (POS) on OID is stronger for employees with stronger exchange ideology. We further argue that employee investment in an organization may also create a social exchange process that positively influences OID. We expect that employee investment moderates not only the effect of POS on OID, but also the enhancing effect of exchange ideology on the effect of POS on OID. Specifically, POS has a stronger positive effect on OID when exchange ideology is high and when employee investment is low. When employee investment is high, POS has a weaker effect on OID regardless of employees' exchange ideology. These effects were empirically supported by a survey. Theoretical and practical implications are also discussed.
\end{abstract}

Key words: Employee-organization relationship; organizational identification; social exchange relationship; perceived organizational support; employee investment; exchange ideology 


\section{Introduction}

Organizational identification (OID) in general refers to the extent to which an organizational member defines himself/herself with reference to his/her organizational membership (Ashforth and Mael, 1989). OID plays a central role in employee-organization relationship, which has been found to lead to a range of positive employee and organizational outcomes (Ashforth, Harrison and Corley, 2008), such as low turnover intention (e.g., Smith et al., 2010; Van Dick et al., 2004), organizational citizenship behaviour (e.g., Van Dick, Grojean, Christ and Wieseke, 2006), employee satisfaction, and well-being (Knight and Haslam, 2010), financial benefits to the organization (Millward and Postmes, 2010), employee performance (e.g., Walumbwa et al., 2011), and employee creativity (Wang and Rode, 2010). Therefore, it is theoretically and practically important to better understand the antecedents of OID (Ashforth et al., 2008; Davenport and Daellenbach, 2011). The purpose of this research is to examine the antecedents of OID from a social exchange perspective.

Recent research has paid increasing attention to the social exchange antecedents of OID, such as perceived organizational support (POS) (Edwards, 2009; Edwards and Peccei, 2010; Gibney et al., 2011; Sluss, Klimchak and Holmes, 2008; Sturges, Conway and Liefooghe, 2010). This line of research incorporates the insights from two major theories of employeeorganization relationship, namely social identity and social exchange. Social identity theory (Tajfel, 1978; Tajfel and Turner, 1985; Turner, 1982; Turner, 1987) and social exchange theory (Eisenberger, Huntington, Hutchison and Sowa, 1986; Snape and Redman, 2010; Song, Tsui and Law, 2009) have traditionally emerged as two largely independent and distinct theoretical bases for explaining the psychological relationship between employees and their organizations. Social identity theory builds on the self-definitional function of social membership and advocates the central role of OID - the perceived oneness between individual and organization - in the employee-organization relationship (Ashforth et al., 2008; 
Ashforth and Mael, 1989). Social exchange theory offers an alternative view, arguing that employee-organization relationship is built on unspecified obligations and employee perception of the quality of the social exchange relationship, which in turn is a function of benefits (i.e., pay, support, investment, and recognition) and personal sacrifice/efforts (CoyleShapiro, Kessler and Purcell, 2004; Cropanzano and Mitchell, 2005; Emerson, 1976; Settoon, Bennett and Liden, 1996; Wayne, Shore and Liden, 1997).

These two theoretical perspectives have developed separately with little crossfertilization or integration (Van Knippenberg, Van Dick and S. Tavares, 2007), until recently when increasing attention has been accorded to the social exchange antecedents of social identification development. For example, perceived organizational justice (Blader and Tyler, 2009; Cheung and Law, 2008; Frazier et al., 2010; Tyler and Blader, 2003; Walumbwa, Avolio and Zhu, 2008) and leader-member exchange(Tangirala, Green and Ramanujam, 2007) have been shown to be important antecedents of OID. In addition, the positive effect of POS on OID has been supported by the results of a number of studies (e.g., Edwards, 2009; Edwards and Peccei, 2010; Sluss, Klimchak and Holmes, 2008). This study aims to extend recent work on the social exchange antecedents of OID by examining the moderating effect of employees' exchange ideology on the effect of POS on OID, and by incorporating the employee investment model (i.e., employee investment in organization stemming from the investment model) in explaining OID.

Exchange ideology is defined as "the strength of an employee's belief that work effort should depend on treatment by the organization" (Eisenberger, Huntington, Hutchinson and Sowa, 1986, p. 503). Employee investment refers to employees' perception about time, efforts, and resources which they have invested in their work organization (Farrell and Rusbult, 1981; Rusbult and Martz, 1995). 
This research makes a number of theoretical contributions to the literature. First, through empirical testing of the main effects of both POS and employee investment on OID, this research offers compelling evidence on the social exchange antecedents of OID. Second, this research extends current knowledge on the social exchange antecedents of OID by supporting the compensating interactive effect between POS and employee investment in influencing OID. Finally, this study advances the literature by identifying how personal value (i.e. exchange ideology) moderates the relationships between social exchange antecedents and OID. The reminder of the paper is structured as follows. First, we present a brief summary of our theoretical framework. Second, we offer detailed theoretical explanation for the associated hypotheses in our theoretical model. Third, the methods and results are presented. Finally, we discuss the theoretical and managerial implications of the research findings obtained in this study.

\section{Theoretical framework and hypotheses development}

\section{A summary of the theoretical framework}

According to social exchange theory, the extent to which social exchange influences the employee-organization relationship depends on a person's exchange ideology. For example, exchange ideology moderates the effect of POS on workplace outcomes, such as absenteeism (Eisenberger et al., 1986). Drawing on similar principles, we expect that a similar moderating effect may apply to other relevant or similar outcomes, such as OID. In addition, according to the investment model of organizational relationships (Farrell and Rusbult, 1981; Rusbult and Martz, 1995), employee investment encourages employees to develop more enduring and stronger relationship with their work organization. Like POS, employee investment may act as another social exchange variable to enhance OID, as escalation of identity-based relationship may be derived from such investment. In addition, high employee investment 
may compensate for low POS in influencing OID in that when employee investment is higher, POS becomes less important to forge employee OID. Given that POS' effect on OID depends on exchange ideology, we expect that when employee investment is high, due to its compensating influence on the effect of POS, the effect of POS would be weaker regardless of exchange ideology. POS would have a stronger effect only when exchange ideology is high and when employee investment is low. Figure 1 illustrates the proposed conceptual framework we tested in this study.

INSERT FIGURE 1 ABOUT HERE

\section{Organizational identification (OID)}

The social identity of an individual refers to the knowledge of a person's membership of a social group and the value and emotional significance attached to that membership (Tajfel, 1978). Social identity theory has been widely applied to explain various phenomena, including employee-organization relationships (e.g., Ashforth and Mael, 1989; Dutton, Dukerich and Harquail, 1994; Ferris, Brown and Heller, 2009; Hogg and Terry, 2001; Olkkonen and Lipponen, 2006). An organization can become a focal and salient social category with which employees can identify (e.g., Alvesson and Willmott, 2002; Ashforth and Mael, 1989; Cornelissen, Haslam and Balmer, 2007; Dutton, Dukerich and Harquail, 1994; Hogg and Terry, 2001). OID occurs when an individual's identity as an organizational member is salient to his/her self-definitional need, and when the person's self-concept has many attributes similar to his/her perceived organizational identity (Gundlach, Zivnuska and Stoner, 2006; Hogg and Terry, 2000).

OID has been seen not only as a major indicator of the employee-organization relationship, but also as a principal antecedent to other organization- and job-related attitudes and outcomes (Ashforth et al., 2008; Carmeli, Gilat and Waldman, 2007; Walumbwa et al., 
2011). Employees with stronger OID tie their self-image with the defining essence of the organization (Fuller et al., 2006). Hence OID leads to some favourable employee attitudes and behaviours within the focal organization, such as job attachment, extra-role behaviours and performance ( Ashforth et al., 2008; Dutton, Dukerich and Harquail, 1994; Hogg and Terry, 2000; Pierce and Gardner, 2004; Riketta, 2005). These favourable outcomes of OID have been widely shown by prior empirical studies. Hence, it is of great importance to ensure stronger OID and understand what leads to OID, and we believe that it is of equal importance to understand under what type of contexts the relationships are much stronger.

\section{Perceived organizational support (POS) and OID}

Social exchange theory posits that individuals engage in social relationships based on the subjective judgments of cost-benefit trade-offs and on the comparison of alternative relationships (Blau, 1964; Cropanzano and Mitchell, 2005; Emerson, 1976). Receiving benefits from another party generates unspecified obligations in return for the benefits, by matching goodwill and helpfulness toward the other party (Masterson, Lewis, Goldman and Taylor, 2000; Settoon, Bennett and Liden, 1996; Tekleab, Takeuchi and Taylor, 2005). Similarly, people may end the relationship when perceived costs are higher than the perceived or expected benefits, given the availability of alternative employment (Blau, 1964). POS, a key social exchange variable, is defined as employees' beliefs on the extent to which the organization values their contributions and cares about their well-being (Eisenberger, Huntington, Hutchison and Sowa, 1986).

As just explained above, social identity and social exchange paradigms have been developed mainly independently and in isolation from each other (van Kinppenberg et al., 2007). This is not surprising given that they differ in at least one assumption regarding employee-organization relationship. As noted by van Knippenberg et al. (2007), "social 
exchange processes imply a relationship in which the individual and the organization are separate entities psychologically [while] identification implies that the individual and the organization are one" (p. 463). Therefore, one barrier or limitation of integrating these two perspectives is related to the difference in their implicit assumptions on the relationship between the two entities: employees and the organization. Although social exchange perspective assumes that the employee and the organization are two different entities, it does not suggest that these two separate entities are not able to be psychologically attached. Similarly, although social identity perspective assumes that the employee and the organization could be one, it does not argue that they are always one. For example, research has shown that, from the social identity perspective, an employee can be psychologically detached from an organization through organizational dis-identification (Elsbach and Bhattacharya, 2001; Kreiner and Ashforth, 2004). Therefore one possible way to break the barrier of integrating social exchange and social identification perspectives is to acknowledge that two separate entities in a social exchange relationship can be bonded into one due to social identification.

Not surprisingly, despite the distinctive assumptions and seemingly unrelated theoretical arguments embedded in social identity and social exchange in explaining employeeorganization relationship, recent scholarly works have begun to explore the ways how they can be integrated. Among these works, most have started to incorporate insights from social exchange theory to explain the development of OID. For example, Wiesenfeld, Raghuram and Garud (2001) found that perceived work-based social support - the degree to which individuals perceive that they have positive social relationships with others in the workplace is positively related to OID among virtual workers. Sluss, Klimchak and Holmes (2008) found that POS mediates the effect of leader-member exchange on OID. Further, POS is positively related to OID, and mediated the effect of HR-related environment on OID (Edwards, 2009). OID is found to mediate the effect of POS on turnover intention and involvement 
(Eisenberger et al., 2001). These studies, besides building on both social exchange theory and social identification theory, also largely drew on or bore some degree of resemblance to (a) prior observation that reciprocity tends to stimulate stronger interpersonal bonds (Eisenberger et al., 2001; Molm, 2003; Rhoades, Eisenberger and Armeli, 2001); and (b) the group engagement model (Tyler and Blader, 2003).

In addition, according to the group engagement model, people feel more organizational respect and self-esteem when they believe that their work organization values and appreciates them (Tyler, 1999). Since self-esteem and self-enhancement are major motives for social identification(e.g., Dutton, Dukerich and Harquail, 1994; Lane and Scott, 2007; Lee and Peccei, 2007), how group members feel about how the group treats them affects how they construct their social identity with reference to their group membership (Tyler and Blader, 2003). Accordingly, the feeling of being valued and appreciated by an organization (POS) makes employees appreciate and trust their organization more and have more confidence in their organization's fulfilment of its exchange obligations (Cropanzano and Mitchell, 2005), and develop stronger organization-based collective identity (i.e. OID). POS is a major indicator of employees' perception of how an organization treats them (Kiewitz, Restubog, Zagenczyk and Hochwarter, 2009; Zagenczyk et al., 2010). In addition, Wiesenfeld, Raghuram and Garud (2001) argue that supportive organizational constituents (incl. supervisors and co-workers) enhance the employees' feeling of being central, included, valued and respected, which in turn leads to a stronger belief that organizational involvement is self-enhancing and attractive, thus stronger motivation for identification with the organization. This process is in alignment with the top-down process of OID development (Ashforth et al., 2008). Thus, based on the above argument, we proposed that: Hypothesis 1: Perceived organizational support is positively related to OID. 
Moderating effect of exchange ideology over POS-OID relationship

Although prior research has supported the positive impact of POS on OID, it is not clear whether the effect of POS on OID would also depend on social exchange beliefs (i.e., exchange ideology) which have been found to moderate the effect of POS on several other relationship quality variables. Exchange ideology describes individual differences in reciprocity beliefs, as individuals can differ in terms of the extent to which they endorse the value of reciprocity (Cropanzano and Mitchell, 2005). Exchange ideology is a personal dispositional orientation that centres on a self-protecting reciprocity belief, as this belief stresses the felt obligation to reciprocate the organization (e.g., helping and care about the organization) only when the organization delivers adequate benefits to the employees. Adding exchange ideology into the social exchange model enables the test of individual differences in the POS and OID relationship.

Employees with stronger exchange ideology endorse the principles of reciprocity more strongly (e.g., Redman and Snape, 2005; Scott and Colquitt, 2007) and are more inclined to behave in line with the predictions of social exchange theory (Eisenberger, Huntington, Hutchison and Sowa, 1986). Taking POS as an indicator of social exchange relationship, employees with high levels of exchange ideology are more likely to value the support they receive from the organization and have a stronger sense of obligation to reciprocate emotionally, if they have benefited or expect future benefits (e.g., organizational support) out of such a relationship (e.g., Frenkel and Sanders, 2007; Lee and Peccei, 2007; Rhoades and Eisenberger, 2002). On the contrary, when exchange ideology is weak, even when organizational support is higher, an employee is less likely to develop a strong relationship with his/her organization due to lack of felt obligation to reciprocate back to the organization.

Similarly, we expect that the effect of POS on OID will be stronger for employees with stronger exchange ideology, as POS will be a more salient driving force for OID development 
for those who place stronger value on reciprocity and value more the support they get from the organization. Employees with stronger exchange ideology tend to reciprocate and develop stronger ties with an organization, when they believe that the organization values, cares about, and supports them (Eisenberger, Huntington, Hutchison and Sowa, 1986) and because they expect that their sustaining contribution to their organization will enable them to receive reciprocity from their organization in future. Therefore when POS is high, employees with stronger exchange ideology are more likely to appreciate and value the support they receive from the organization, and hence are more likely to identify with their focal organization. This proposition is in alignment with the theoretical narrative of the group engagement model, which argues that how the employees feel they are treated by an organization affects their group-based social identity (e.g., Blader and Tyler, 2009). More importantly, our proposition extends this central argument by suggesting that group engagement strength depends on exchange ideology.

Prior research has found the enhancing effect of exchange ideology on social exchange variables (particularly POS) in a number of contexts with different workplace outcomes as dependent variables. For example, Eisenberger et al. (1986) find that the relationship between perceived organizational support and absenteeism was greater for school teachers with a stronger exchange ideology. Perceptions of organizational support were more salient in the decision to be absent from work for those individuals whose predisposition was to perform in a manner consistent with reinforcement and felt obligated to reciprocate the organization for its support. Witt (1992) found that exchange ideology enhances the effects of participation in decision making on job attitudes. Exchange ideology has also been found to enhance the effects of procedural justice on employee commitment (Witt, Kacmar and Andrews, 2001) and satisfaction with training experience (Witt and Broach, 1993). Scott and Colquitt (2007) determined that exchange ideology moderated the effects of organizational justice on a 
number of employee outcomes, citizenship behaviour and task performance. Ladd and Henry (2000) found that exchange ideology enhanced the effect of POS on organizational citizenship behaviours. Exchange ideology also enhances the negative effect of employee perception of organizational politics on retention (Andrews, Witt and Kacmar, 2003). Thus,

Hypothesis 2: Exchange ideology moderates the positive relationship between perceived organizational support and OID, so that the positive relationship is stronger for employees with stronger exchange ideology.

\section{The main and moderating effects of employee investment}

According to the investment model of social exchange (Farrell and Rusbult, 1981; Rusbult and Farrell, 1983), investment refers to resources a person's perception that he or she has put into a relationship (e.g., friendship, marital, job, and organizational) that have become intrinsic to the relationship (Goodfriend and Agnew, 2008; Rusbult, Farrell, Rogers and Mainous, 1988; Rusbult, Martz and Agnew, 1998). For example, in the context of romantic relationship, it has been found that a person's commitment to a relationship depends on not only the expected relationship outcome or the quality of best available alternative, but also the individual's investment in the relationship (Rusbult, 1980). Regarding employee-organization relationships, employee investment refers to resources which employees invest consciously or unconsciously in their work organization (Blau, 1964; Farrell and Rusbult, 1981; Hrebiniak and Alutto, 1972; Kanter, 1968 ; Rusbult and Farrell, 1983). Typical employee investment includes specific job/work-related training, investment in building personal relationship with colleagues and supervisors, and socializing into the organizational culture and climate. As noted by Farrell and Rusbult (1981), "Investments refer to the resources that are 'put into' an association, usually, but not necessarily, with the intent to improve the long-term value of the relationship. Length of service, acquisition of non-portable skills, and retirement programs are 
common job investments" (p. 81-82). According to the investment model, an individual's organizational/job commitment (i.e., the strength of identification with and involvement in a particular organization) depends on not only the rewards and costs associated with the job or the quality of job alternatives, but also the magnitude of the individual's investment in the job/organization (Farrell and Rusbult, 1981). It is important to note that employee investment differs from continuance commitment. Continuance commitment refers to employees' perceptions of the costs associated with leaving the organization (Allen and Meyer, 1990). Despite the highly possible positive correlation between employee investment and continuance commitment due to the increases costs of leaving derived from investment, investment refers to tangible and psychological resources, whilst continuous commitment refers to a psychological state of mind (i.e., perception of costs) that are closely related to hypothetical future withdraw. Nevertheless, employee investment has significant implications for explaining social exchange relationships, although it has received much less attention than POS.

Employee investment in an organization positively affects his or her OID for several reasons. First, employee investment can be seen by employees as one side of the reciprocal form of social exchange which engenders a better inter-party bond (Farrell and Rusbult, 1981; Rusbult and Martz, 1995), which in an organizational setting refers to the person-organization bond (Molm, 2003). Such a psychological bond is a significant basis for people to identify with their focal organizations (Dutton, Dukerich and Harquail, 1994). Second, according to the investment model, when people invest more in a relationship, they tend to be more dependent on the organization, both materially and psychologically, which in turn enhances the costs of ending the relationship and affective attachment to (i.e., identification with) the other party in the focal relationship (Rusbult, 1983; Rusbult et al., 1998). The enhanced costs of ending a relationship serve as a powerful psychological mechanism of relationship 
persistence, despite that sometimes the values of alternative relationships or relationship satisfaction are high (Rusbult et al., 1998).

Third, as employee investment accumulates, employees' organizational membership gets stronger and more salient, which in turn, according to social identification theory, leads to stronger OID. Ashforth et al. (2008) argue that despite the fact that most existing OID research focuses on top-down identification, individual level factors (e.g., sex, bio-data, organizational tenure, and person-organization fit) may predict bottom-up OID. Employee investment facilitates person-organization fit and more organizational contacts with and exposure to organizational culture (e.g., rituals, ceremonies, symbols, etc.), thus tends to encourage a bottom-up identification process. Furthermore, higher employee investment is associated with various organizational cultural elements, such as artifacts, rituals, ceremonies, etc. (Wiesenfeld, Raghuram and Garud, 2001). Meanwhile research on OID suggests that exposure to organizational artifacts, symbols, rituals, and ceremonies are positively related to the strength of OID (e.g., Dutton, Dukerich and Harquail, 1994; Islam and Zyphur, 2009).Thus when employees invest more time in their organization with regard to being more exposed to these organizational elements, they are more likely to identify with the organization.

It is also important to note that OID may lead to higher employee investment. Because this research focuses on one side of the coin (the main and moderating effects of employee investment on OID), we operationalize employee investment as an accumulated investment from past organizational activities, instead of employee intention to invest more in an organization. OID, on the other hand, tends to capture employees' state of mind. Therefore, it is more logical to expect prior accumulated employee investment to affect current state of OID. Thus, 
Hypothesis 3: Employee investment is positively related to employees' identification with the organization.

Moreover, we argue that employee investment compensates the role of POS in driving OID. POS and employee investment both rely on similar but also slightly different social exchange mechanisms for the development of employees' OID. As noted earlier, POS motivates OID for the exchange the employee receives from the organization; whilst organization investment encourages OID for what the employee invests in the organization. When employee investment is high, employees are more embedded in the organization, which in turn makes employees more psychologically attached to the organization (Farrell and Rusbult, 1981). It is possible that POS and employee investment might be correlated in that employees may be more inclined to invest more in an organization when they perceive stronger support from the organization and an organization might offer stronger support to those who have invested hence committed more to the organization. However, POS and employee investment are two unique forces that drive employee OID. We can easily find or imagine cases where despite strong support from a romantic partner, the other party may not be emotionally attached to the relationship due to lack of personal investment hence commitment to the relationship. Similarly, in the employee-organization relationship, we can also imagine cases where employees might lack identification with an organization, despite the support they receive from the organization, due to insufficient investment in or connection with the organization. These two forces of OID are unique particularly in terms of the sources of emotions. For POS, the source comes from the other party, whilst for employee investment, the sources resides on the individual, particularly his/her personal choice and will. Therefore, we argue that the personal choice and will is stronger (i.e., higher employee investment), the emotional attachment with an organization will less susceptible to the doing of the third party 
(e.g., the organizational support they receive from the organization). Hence when employee investment is higher, the effect of POS on OID will be weaker.

Hypothesis 4: Employee investment moderates the effect of perceived organizational support on OID. When organization investment is higher (lower), perceived organizational support has a weaker (stronger) effect on OID.

Prior discussion established that POS has a main effect on OID (e.g. Edwards and Peccei, 2010; Gibney et al., 2011; Sluss, Klimchak and Holmes, 2008; Sturges, Conway and Liefooghe, 2010), and that this effect tends to be stronger when exchange ideology is stronger or when employee investment is lower. These contrasting moderating effects of exchange ideology and employee investment, due to their unique theoretical moderating mechanisms, suggest a joint moderating effect by these two variables on the effect of POS on OID. One possibility is that, as noted earlier, the effect of POS on OID tends to be mitigated by high employee investment. This weaker effect of POS on OID (when employee investment is high) suggests that the effect of POS on OID would be insignificant for employees regardless of their exchange ideology strengths. However, when employee investment is lower, the stronger effect of POS on OID is more likely to be susceptible to the principles of reciprocity that are embedded in social exchange relationship, therefore the effect of POS on OID would be even stronger when the exchange ideology is higher. On the other hand, when exchange ideology is low, the effect of POS on OID tends to be already too insignificant to be moderated by employee investment. In other words, for employees with weaker exchange ideology, due to the absence of meaningful effect of POS on OID, there is little effect of POS regardless of the level of employee investment. In sum, the contrasting moderating effect of exchange ideology and employee investment suggests that exchange ideology and employee investment would neutralize each other's moderating effect. Thus, POS would have a stronger effect of OID 
especially when exchange ideology is higher and when employee investment is lower. Thus we expect,

Hypothesis 5: Perceived organizational support has a stronger effect on $\mathrm{O}$ when exchange ideology is high and when employee investment is low.

\section{Method}

Sample

Five hundred and two white-collar employees from Vietnamese organizations (ten in Hanoi city and seven in Ho Chi Minh City) took part in the study. Among the seventeen organizations, six are in the banking and investment sector; five are in the oil \& gas sector; the rest companies are in construction, transportation, hospital, pharmacy, electric products, and architecture. We considered the trade-off among the number of companies, the number of questionnaires for each company, and the reliability of the questionnaire administration. As we delivered questionnaires through the HR managers, after interviewing some of them, we identified that to ensure that the HR managers can keep the process as standard as we expected (population criteria, representative of the company population, and ultimate confidentiality), the number of questionnaires delivered in each company should be around 50 . We instructed the HR managers to keep the sample as representative as possible. Individuals were selected based on three criteria: the participants (a) were Vietnamese and worked for organizations in Vietnam; (b) were formal entry-level or mid-management employees; and (c) held a bachelor's or higher degree. Participation was anonymous, voluntary and unpaid. Fourteen firms agreed to deliver 50 questionnaires and three agreed to deliver 100 questionnaires, with a total of 1000 questionnaires delivered. The questionnaires were returned directly to one of the co-authors, who administered the survey onsite. Of these, 536 were returned, of which $502(93.76 \%)$ were usable. This represents an effective response rate 
of 50.20\%, above the norm of response rates in academic studies (Baruch and Holtom, 2008). Non-response bias was minimized by senior managers' cooperation in delivering the questionnaire to a sample that is representative of their firm's population in terms of age, gender, and family background. We also reported the sample demographic profile back to the senior managers, and asked them to check the samples' representativeness.

Gender distribution was balanced, with $51.69 \%$ males and $48.31 \%$ females. The average age was 31.61 years (ranging from 20 to 60 ) with $85 \%$ under the age of 40 years, consistent with the young labour force in Vietnam. Over half $(56 \%)$ of the respondents worked in the South while the rest $44 \%$ worked in the North of Vietnam. About $54 \%$ of the respondents worked in the industrial sector and the rest were employed in the service sector. A standard translation and back-translation procedure was applied to the survey questions (Sperber, Devellis and Boehlecke, 1994). A pilot study was conducted with 54 employees in Vietnam to examine the questionnaire further. The results of the pilot indicated no need for more than minor grammatical adjustments.

\section{Measures}

Responses to the items were made on seven-point Likert scales, ranging from "strongly disagree" (1) to "strongly agree" (7). OID was measured using a widely used five-item scale (Mael and Ashforth, 1992). POS was measured by six-item scale excerpted from the original scale developed by Eisenberger and colleagues (Eisenberger, Huntington, Hutchison and Sowa, 1986). A shortened form is considered adequate, as prior research shows that POS is a unidimensional construct (Rhoades and Eisenberger, 2002). Rusbult and Farrell's (1983) three-item scale was used to measure employee investment, which has also been applied to specific contexts in prior research (e.g., Oliver, 1990; Rusbult and Martz, 1995; Rusbult, Martz and Agnew, 1998). Exchange ideology was measured using eight items from 
Eisenberger et al.'s (2001) scale. Three reverse-coded items were removed, as they loaded into a separate factor (see e.g., Netemeyer, Bearden and Sharma, 2003; Swain, Weathers and Niedrich, 2008). Prior research has also used only the five main items (e.g., Scott and Colquitt, 2007). Table 1 presents the final measurement items and loading values obtained using exploratory factor analysis (EFA). All measures in the study are self-reported. Self-report has been argued to be appropriate for variables that are perceptual or related to private events (Chan, 2009; Conway and Lance, 2010). Self-report ratings are not considered to be inferior to other type of subjective rating, such as supervisor or peer rating (Conway and Lance, 2010).

\section{INSERT TABLE 1 ABOUT HERE}

\section{Results}

\section{Scale Validity}

We first tested the severity of common method variance, given that all variables were measured with one single instrument. Harman's single factor exploratory factor analysis (EFA) using principal component analysis, without Varimax rotation, revealed four factors, with the first factor accounting for $34.05 \%$ of the total variance. EFA with Varimax rotation revealed that the four factors correspond exactly to the measurement scales for the four constructs (see Table 1). We further ran a confirmatory factor analysis (CFA) version of Harman's single factor test (Podsakoff et al., 2003). Single factor CFA produced an extremely poor fit $(\chi 2=$ $\left.2239.997(152), \chi^{2} / \mathrm{df}=14.74, \mathrm{RMSEA}=0.17 ; \mathrm{CFI}=0.57, \mathrm{TLI}=0.46\right)$, as compared to the four-factor measurement model. The four-factor measurement model achieved adequate fit: $\chi^{2}=526.29(146), \chi^{2} / \mathrm{df}=3.61, \mathrm{RMSEA}=0.07 ; \mathrm{CFI}=0.92, \mathrm{TLI}=0.90$. All of the estimated factor loadings of the indicators for the underlying constructs (see Table 1) are larger than the .5 benchmark (Hair et al., 2006) and are significant $(p<.001)$. We further test the common method variance by comparing the proposed four-factor measurement model 
with a series of three-factor measurement models that combined any two of the variables (see e.g., Hekman, Bigley, Steensma and Hereford, 2009; Hekman, Steensma, Bigley and Hereford, 2009). Appendix A presents the full results of model fit comparison. It clearly shows that four-factor measurement model is superior to all comparative factor models.

Table 2 also presents the descriptive statistics, average variance extracted and composite reliabilities of all measures in the measurement model. Cronbach's alpha estimate of the reliability of the constructs exceeded the 0.70 threshold (Nunnally, 1978). The average variance extracted (AVE) of most constructs exceeded the 0.5 benchmark, except for exchange ideology (0.47), which is slightly lower but very close to that benchmark. However, other criteria for exchange ideology are above recommended threshold (alpha $=0.77$; composite reliability $=0.81)$. The square roots of all AVE scores are higher than the correlations of any pairs involving the focal variable, which supports the discriminant validities of the scales (Fornell and Larcker, 1981). Taken together, these tests support the convergent and discriminant validities of the scales used, and suggest little concerns for the common method bias to confound the findings.

In addition, common method variance poses less a concern of bias for the present study, as we aim to test and find some significant interactive effects (Evans, 1985; Siemsen, Roth and Oliveira, 2010). Evans (1985) finds that significant interactive effects cannot be created artificially by correlated errors (which can be mainly caused by common method). Also a more recent study (Siemsen, Roth and Oliveira, 2010) shows that 'quadratic and interaction effects cannot be artefacts of common method variance. On the contrary, both quadratic and interaction terms can be severely deflated through common method variance, making them more difficult to detect through statistical means. Therefore, finding significant interactive effects is very unlikely to be caused by common method variance. 
INSERT TABLE 2 ABOUT HERE

\section{Hypotheses testing}

Moderated structural equation modelling (SEM) was used to conduct hypotheses testing with M-PLUS 6.0 (Muthén and Muthén, 1998-2010). SEM moderation models can perform better than traditional moderated regression analyses because SEM models can take all regression paths and variances into account in one Model (Iacobucci, Saldanha, \& Deng, 2007). The M-PLUS program provides the correct parameter estimates and standard errors, and can deal with non-independence of ratings of all the variables among different employees within one company under the influence of the same culture and environment of a company. This becomes particularly useful to analyse the data because our sample comes from different organizations. Through the command of "type $=$ complex," M-PLUS provides a general way to adjust for clustering or classification in data analysis taking non-independence of observations among different employees within the same company into account. We conducted three models to test the hypotheses, and the SEM results were shown in the Table 3. For all models, we added three control variables: age, gender, and management. Age and gender are typical control variables for OID and general OB research (see e.g., Riketta, 2005). We controlled for management level, which is defined as whether the employees have any supervisory role. It was coded as a dummy variable: coded 1 for those with supervisory role, otherwise 0 . Management position might be related to OID as people at different hierarchical levels in an organization may influence their OID. This is particularly important for our study, as managers and ordinary employees might have different levels of investment in their organizations, as our result (in Table 2$)$ shows that they are significantly correlated $(\mathrm{r}=.10, p$ $<.05)$. 


\section{INSERT TABLE 3 ABOUT HERE}

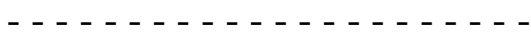

Main effect model. Model 1 is used to examine the main effects of POS, exchange ideology, and employee investment on the dependent variable, OID. The data fits the proposed theoretical model $\left(\chi^{2}=550.74, \mathrm{df}=236, \mathrm{CFI}=.91, \mathrm{TLI}=.90, \mathrm{RMSEA}=.05\right.$, $\left.\mathrm{SRMR}=.06 ; \mathrm{R}^{2}=.50\right)$. None of the control variables were significantly related to the outcome variable. As expected, POS was found to have a significant and positive relationship $(\beta=.40, p<.01)$ with OID. Therefore, Hypothesis 1 , which proposed that perceived organizational support is positively related to OID, was supported. Employee investment was found to have a significant and positive relationship $(\beta=.35, p<.01)$ with OID. Thus, Hypothesis 3 is supported. Model 1 also finds that exchange ideology is negatively related to OID $(\beta=-.23, p<.01)$.

Two-way interaction model. Model $2\left(\chi^{2}=617.04 . \mathrm{df}=290, \mathrm{RMSEA}=.05, \mathrm{CFI}=.91\right.$, TLI=.90, SRMR=.06; $\mathrm{R}^{2}=.54$ ) adds three two-way interactions into the model, which enables the test of the hypothesis that involves the moderating effects of exchange ideology and employee investment on the effect of POS on OID. The regression effect of the interaction term of exchange ideology and POS on OID is significant $(\beta=.12, p<.01)$. We plotted Figure 2 to illustrate the simple slope difference regarding the effect of POS under high or low (one standard deviation above or below the mean) levels of exchange ideology ${ }^{1}$. Figure 2 clearly shows that when exchange ideology is high, POS has a stronger positive effect on OID. Therefore, hypothesis 2 , which proposed that the relationship between perceived organizational support and OID is moderated by exchange ideology, was supported.

\footnotetext{
${ }^{1}$ To allow for a more accurate representation of the graph, we explicitly estimate the intercepts and means in the SEM models.
} 
Hypothesis 4 predicts that employee investment alleviates the effect of POS on OID. Hypothesis 4 is supported as indicated by the significant effect of the interaction term $(\beta=-$ $.19, p<.01)$. Figure 3 illustrates the pattern of this interactive effect. It shows that POS has a stronger effect on OID when employee investment is low.

\section{INSERT FIGURE $2 \& 3$ ABOUT HERE}

Three-way interaction model. To test hypothesis 5, which predicts that POS has the strongest effect on OID when exchange ideology is high and when employee investment is low, we ran Model 3. Model $3\left(\chi^{2}=662.08, \mathrm{df}=308, \mathrm{RMSEA}=.05, \mathrm{CFI}=.90, \mathrm{TLI}=.89\right.$, SRMR = .06; $\left.\mathrm{R}^{2}=.55\right)$ adds the three-way interaction involving POS, exchange ideology and employee investment into the SEM analysis. The three-way interaction's coefficient on OID is significant $(\beta=.15, p<.01)$. We plotted this interaction to illustrate the pattern of the effect of POS on OID under high or low levels of both exchange ideology and employee investment (see Figure 4). We further did simple slope difference test among the conditional effects of POS on OID. Figure 4 shows that POS has the strongest positive effect on OID when exchange ideology is high and when employee investment is low (Slope 2). Slope 2 is significantly different from the other three slopes $(\mathrm{p}<.001$ in all cases). There is no significant difference among the other three slopes. Therefore hypothesis 5 is supported.

\section{INSERT FIGURE 4 ABOUT HERE}

\section{Discussion}

\section{Theoretical implications}

The most important theoretical contribution of this study is that it extends how the social exchange antecedents of OID development are conceptualized. Recent studies have 
consistently found that there is a main positive effect of perceived organizational support on OID (e.g., Edwards and Peccei, 2010; Sluss, Klimchak and Holmes, 2008). Our study provides further evidence on the effect of POS on OID. While these studies draw our attention to a new line of research on the antecedents of OID from the social exchange perspective, they also tended to rely on only the social exchange perspective to explain these relationships. These prior studies did not test the conditional effect of POS on OID with reference to the key moderator of exchange relationship (i.e., exchange ideology) and employee investment in an organization.

First, this research contributes to prior literature on social exchange antecedents of OID by supporting the moderating effect of exchange ideology on the relationship between POS and OID. This result not only confirms prior research findings that exchange ideology may strengthen the effect of POS on some outcome variables, but also extends this line of argument and reasoning to a social identity-based relationship (i.e., OID). This in turn provides further evidence on the antecedent role of POS on OID, as it not only supports the main effect of social exchange relationship on OID, but also is consistent with the earlier theoretical prediction of social exchange perspective of employee-organizational relationship. Social exchange beliefs (i.e., exchange ideology) strengthen the effect of social exchange quality (i.e., POS).

Drawing on the investment model of social exchange (Farrell and Rusbult, 1981; Rusbult and Farrell, 1983), the study successfully supports that employee investment, in addition to - POS, positively relates to OID. Moreover, employee investment compensates for the role of POS in explaining OID. To our knowledge, this is one of the first studies that propose and empirically support that OID can be positively enhanced by employee investment. The investment model has been widely applied in explaining personal relationship in the psychology literature (see Le and Agnew, 2003 for a meta-analytical review). Although the 
employee investment perspective has been applied to the organizational relationship in the earlier literature, it has not received sufficient attention more recently, as compared to attention given to POS. Our results suggest that in the social exchange relationship in organizational settings, both POS and employee investment are important antecedents of OID. These are important observations because they offer strong evidence that an employee's organizational membership-based self-concept (i.e., OID) can be developed through of both sides of the social exchange process (POS and employee investment). This is clearly demonstrated by our results showing that when both POS and employee investment are in the same model predicting OID, both have a significant effect on OID simultaneously.

POS and employee investment represent two similar but distinct social exchange forces in forging a strong and meaningful employee-organization relationship. When employee investment is low, due to low psychological (and tangible) costs of emotionally detaching from the organization, POS plays a greater role in forging stronger employee emotional ties with the organization. When employee investment is high, employee identification becomes less susceptible to organizational support. Moreover, the moderating effect of employee investment goes beyond its main moderating effect on POS, but also moderates the moderating effect of exchange ideology on the relationship between POS and OID. When employee investment is high, POS tends to have a weaker effect on OID regardless of exchange ideology. In other words, both the main and the enhanced effect (conditional on stronger exchange ideology) of POS are weakened by employee investment. This finding clearly extends prior research on social exchange theory by suggesting that individual differences (i.e., exchange ideology orientation) in the effect of social exchange quality on employee workplace outcomes is subject to further conditions, such as employees' investment in the relationship. 
In a broader picture, the findings regarding POS and employee investment contributes to the emerging line of research that incorporates insights of social identity perspective with other perspectives in explaining employee-organization relationship. This broader issue not only focuses on POS, but also examines other perspectives, such as (in) justice (e.g., Blader and Tyler, 2009; Olkkonen and Lipponen, 2006) and perceived psychological contract breach or violation (Kreiner and Ashforth, 2004).

The negative effect of exchange ideology on OID is both surprising and theoretically plausible. It is surprising, because on the one hand, most prior studies treat exchange ideology as a neutral personal dispositional variable, which mainly acts as a moderator on the effect of social exchanges (e.g., POS) on some social exchange outcome variables, such as citizenship behaviour, absenteeism, and task performance (Redman and Snape, 2005; Scott and Colquitt, 2007). On the other hand, employees with stronger exchange ideology are more opportunistic and calculative (Eisenberger, Huntington, Hutchison and Sowa, 1986) and self-interest oriented (Redman and Snape, 2005). They are more likely to terminate their relationships with an organization when felt support and appreciation by the organization is absent. In other words, their organization relationships are driven more by what they receive from the organization. Ashforth et al. (2008) suggest that OID may develop out of an individual's difference in thoughts and beliefs. Exchange ideology is a personal dispositional orientation variable that stresses the differences in people's beliefs in the justice and social acceptance of social exchange reciprocity in organizational settings. Given that people with stronger beliefs in this social exchange reciprocity may often place less emphasis on social identity motives (e.g., group status and social belonging), they are less likely to develop strong OID.

It is therefore not surprising to find that exchange ideology is negatively related to OID. Although not focusing on OID per se, prior studies find the negative effects of exchange ideology on organizational citizenship behaviours (Ladd and Henry, 2000; Scott and Colquitt, 
2007), task performance (Scott and Colquitt, 2007), and the quality of employees' social exchanges with the organization (i.e., felt obligation) and with a leader (Takeuchi, Yun and Wong, 2011); and positive effects on intention to quit unions and to switch unions (Redman and Snape, 2005). Our finding (i.e., the negative effect of exchange ideology on OID) and those of the above studies suggest that OID may act as one psychological mechanism through which exchange ideology negatively affects work attitudes and behaviours (e.g., citizenship behaviours, performance, and turnover intention), because OID has also been found to be an important antecedent of employee work attitudes and behaviours. In addition, the negative effect of exchange ideology on OID also collaborates the finding of van Knippenberg et al. (2007), which finds that POS and OID negatively interact to predict employee turnover intention and absenteeism. Thus both studies suggest that although it is possible to integrate social exchange perspective and social identity perspective, how it occurs may depend on both the specific social exchange variables and the dependent variables. Van Knippenberg et al.'s (2007) study suggests that when the dependent variables are related to employee's attitudes towards the (ending or continuity) of an employee-organizational relationship, POS and OID may negatively interact to influence such attitudes. However, this research and many previous studies suggest that social exchange variables may influence the development of OID. Finally, this research suggests that although social exchange variables may influence OID, different social exchange variables may have different effects. On one hand, POS and employee investment, as positive interaction between the employee and the organization, are positively related to OID. On the other hand, exchange ideology (as a personal belief on social exchange paradigm) is negatively related to OID or other types of employee-organization relationships, due to the strength of personal inclination toward social exchange ideology at the expense of other types of relationship beliefs. 
Another strength of this study is using a sample from Vietnam, a country that has national and organizational culture significantly different from Western organizations and has been under-researched. Vietnam's culture may differ from Western culture in many aspects, such as collectivism vs. individualism, power distance, uncertainty avoidance, and so on (Hofstede, 2003). Successful testing of our proposed theoretical model deriving from Western theories in a different cultural context enhances the generalizability of not only the general constructs but also their theory-derived and empirically-supported relationships.

Several prior-confirmed relationships in the Western context were also supported in this study. These relationships include: the effect of POS on OID and the effect of employee's investment on OID. Although the latter relationship has not been tested in organizational settings, it has been widely supported by the inter-personal relationship literature. Although the other relationships investigated by this study have not been tested in Western cultures, these relationships may be applicable to Western cultures because of their Western theoretical foundations. While certainly, we should be cautious in making universal claims for empirically-supported relationship from a specific context, generalizing these findings to Western cultures appears promising.

\section{Managerial implications}

Our findings underscore the crucial role that social exchange plays in developing OID. The significant positive effects of POS and employee investment on OID suggest that organizations should provide strong organizational support for employees and encourage employees to invest more within the organization. While prior studies on OID advocate investment and management of organizational identities and images, our study suggests that OID management should also take into consideration social exchange factors by supporting employee development and encouraging employee investment in the work organization. 
Following the positive effect of employee investment on OID, we suggest that one way to encourage employee OID is to offer opportunities for employees to invest more in aspects that are related to the organization. This is also because high employee investment may compensate for low POS in encouraging employee OID development. The compensatory nature of employee investment on the main and conditional effect (as conditional on exchange ideology) of POS on OID also suggests that organizations should pay particular attention to those employees with lower employee investment, as they are more likely to be emotionally detached from the organization, but stronger organizational support can prevent them from doing so.

One practical implication from the enhancing effect of exchange ideology on the effect of POS on OID is that organizations should particularly offer stronger organizational support to those who value social exchange and reciprocity principles. It also suggests that it is important for organizations to monitor and identify the levels of employee exchange ideology so that more tailored organizational support can be offered accordingly. The interactive effect of POS and exchange ideology also implies that although exchange ideology may have a main negative effect on OID, higher POS will mitigate such negative effect. This in turn suggests the significant value of offering stronger organizational support for employee OID development. In most cases, because exchange ideology is a personal dispositional orientation, hence less susceptible to organizational management and control, one way to neutralize the potential liability of employees with stronger exchange ideology is to offer them more support so that stronger employee reciprocity is warranted.

\section{Limitations and future research}

This study has some limitations that suggest important future research avenues. First, this study focuses mainly on two critical variables, perceived organizational support and 
employee investment, as the social exchange antecedents of OID. Although we believe that, as an important step to extend the recent debate on social exchange antecedents of OID, it is theoretically sound to focus mainly on organizational-level factors (i.e., POS, employee investment and OID); further research should examine both social exchange and social identity factors at different levels within an organization. For example, team/group identification has been an increasingly promising construct within the social identity perspective in explaining employee-organization relationship (Millward, Haslam and Postmes, 2007), similarly to leader identification (Wang and Rode, 2010). Similarly, leader-member exchange has also been incorporated, with perceived organizational support as an additional social exchange variable, explaining employee-organization relationships (e.g., Erdogan and Enders, 2007). It would be particularly interesting for future research to test multi-level models that integrate social exchange and social identity variables at different levels: individual, group and organization.

Second, this study is based on a cross-sectional data. Future research should go beyond cross-sectional designs and employ longitudinal or experimental research designs to test the hypotheses proposed by the present study, and to examine the causality of the relationships found in this study. The longitudinal method would be particularly useful to test the mutual interrelationship between employee investment in an organization over time and the continuous possible temporal variation in employee OID. Another limitation of this study's sample relates to its selection of only white-collar entry-level and mid-level management employees (with a bachelor's or higher degree). Therefore, we think it is beneficial for future studies to collect data from companies with more diversified employee characteristics, including employee education and other interesting categories, from more industries. In addition, this study has a limitation of uneven response rates from different organization. However, the results should not have been affected significantly for the following five factors: 
relatively large total sample; the lowest response rate being still quite reasonable (24\%); overall effective response rate being high (50.2\%); representativeness of the sample; and controlling for the potential clustering effect of organizations in the analysis.

Fourth, it is possible that POS and employee investment can be related. For example, POS can predict employee investment because employees are more likely to invest more resources to an organization, which they get more support from. On the other hand, when employees invest more in an organization, they are likely to evaluate their organization's support in a more favourable way due to enhanced psychological attachment to the organization. However, our study, based on a cross-sectional design, assumes that both constructs are correlational in nature; therefore we do not propose any causal relationship between them. More importantly, we did find that both POS and employee investment are significantly related to OID, which supports that POS and employee investment can independently predict OID.

Finally, although this study is based on a large and comprehensive data set from an Eastern culture, including a number of different types of organizations, caution should be used when generalizing the findings to other cultural contexts. It is out of the scope of the present study to examine how all the relationships in our study may occur or differ in different cultural contexts. In this regard, future research can conduct cross-cultural studies to shed light on the extent to which the impact of POS on employees' identification with the organization is culturally bound. It is of particular theoretical interest to examine whether our findings are replicable in more individualistic cultures in which interpersonal relationships are less important, but more transactional relationship are important to organizational effectiveness. More specifically, since Vietnam is a relationship-oriented culture, characterized by collectivistic values, individuals tend to work harder to develop and maintain social relationships than in more individualistic societies (Farth, Leong and Law, 1998). 
Social relationships in more collectivist cultures, as compared to more individualistic cultures, are characterized by strong emotional underpinnings, which grow stronger as both parties engage in a process of social reciprocity (Tan and Chee, 2005). Future research can test our model in the Western cultures and compare the applicability of the model cross-culturally. 


\section{References}

Allen, N. J. and J. P. Meyer (1990). 'The measurement and antecedents of affective, continuance and normative commitment to the organization', Journal of occupational psychology, 63(1), 1-18

Alvesson, M. and H. Willmott (2002). 'Identity Regulation as Organizational Control: Producing the Appropriate Individual', Journal of Management Studies, 39(5), 619-644. Andrews, M. C., L. A. Witt and K. Michele Kacmar (2003). 'The Interactive Effects of Organizational Politics and Exchange Ideology on Manager Ratings of Retention', Journal of Vocational Behavior, 62(2), 357-369.

Ashforth, B. E., S. H. Harrison and K. G. Corley (2008). 'Identification in Organizations: An Examination of Four Fundamental Questions', Journal of Management, 34(3), 325-374.

Ashforth, B. E. and F. Mael (1989). 'Social Identity Theory and the Organisation', Academy of Management Review,14(1), 20--39.

Baruch, Y. and B. C. Holtom (2008). 'Survey Response Rate Levels and Trends in Organizational Research', Human Relations, 61(8), 1139-1160.

Blader, S. L. and T. R. Tyler (2009). 'Testing and Extending the Group Engagement Model: Linkages Between Social Identity, Procedural Justice, Economic Outcomes, and ExtraroleBehavior', Journal of Applied Psychology, 94(2), 445-464.

Blau, P. M. (1964). Exchange and Power in Social Life. John Wiley, New York.

Carmeli, A., G. Gilat and D. A. Waldman (2007). 'The Role of Perceived Organizational Performance in Organizational Identification, Adjustment and Job Performance', Journal of Management Studies, 44(6), 972-992.

Chan, D. (2009). 'So Why Ask Me? Are Self-Report Data Really That Bad?'. In: C. E. Lance and R. J. Vandenberg (eds.), Statistical and Metholodogical Myths and Urban Legends: 
Doctrine, Verity and Fable in the Organizational and Social Sciences, Routledge, New York.

Cheung, M. F. Y. and M. C. C. Law (2008). 'Relationships of Organizational Justice and Organizational Identification: The Mediating Effects of Perceived Organizational Support in Hong Kong', Asia Pacific Business Review, 14(2), 213-231.

Conway, J. and C. Lance (2010). 'What Reviewers Should Expect from Authors Regarding Common Method Bias in Organizational Research', Journal of Business and Psychology, 25(3), 325-334.

Cornelissen, J. P., S. A. Haslam and J. M. T. Balmer (2007). 'Social Identity, Organizational Identity and Corporate Identity: Towards an Integrated Understanding of Processes, Patternings and Products', British Journal of Management, 18(S1), 1-16.

Coyle-Shapiro, J. A. M., I. Kessler and J. Purcell (2004). 'Exploring Organizationally Directed Citizenship Behaviour: Reciprocity or 'It's my Job'?', Journal of Management Studies, 41(1), 85-106.

Cropanzano, R. and M. S. Mitchell (2005). 'Social Exchange Theory: An Interdisciplinary Review', Journal of Management, 31(6), 874-900.

Davenport, S. and U. Daellenbach (2011). "Belonging' to a Virtual Research Centre: Exploring the Influence of Social Capital Formation Processes on Member Identification in a Virtual Organization', British Journal of Management, 22(1), 54-76.

Dutton, J. E., J. M. Dukerich and C. V. Harquail (1994).'Organizational Images and Member Identification', Administrative Science Quarterly, 39(2), 239-263.

Edwards, M. R. (2009). 'HR, Perceived Organisational Support and Organisational Identification: An Analysis After Organisational Formation', Human Resource Management Journal, 19(1), 91-115. 
Edwards, M. R. and R. Peccei (2010). 'Perceived Organizational Support, Organizational Identification, and Employee Outcomes: Testing a Simultaneous Multifoci Model', Journal of Personnel Psychology, 9(1), 17-26.

Eisenberger, R., S. Armeli, B. Rexwinkel, P. D. Lynch and L. Rhoades (2001).

'Reciprocation of Perceived Organizational Support', Journal of Applied Psychology, 86(1), $42-51$.

Eisenberger, R., R. Huntington, S. Hutchison and D. Sowa (1986). 'Perceived Organizational Support', Journal of Applied Psychology, 71(3), 500-507.

Elsbach, K. D. and C. B. Bhattacharya (2001). 'Defining who you are by what you're not: Organizational disidentification and the National Rifle Association', Organization Science, 12(4), 393-340-314.

Emerson, R. M. (1976). 'Social Exchange Theory', Annual Review of Sociology, 2, 335-362. Erdogan, B. and J. Enders (2007). 'Support From the Top: Supervisors' Perceived Organizational Support as a Moderator of Leader-Member Exchange to Satisfaction and Performance Relationships', Journal of Applied Psychology, 92(2), 321-330.

Evans, M. G. (1985). 'A Monte Carlo Study of the Effects of Correlated Method Variance in Moderated Multiple Regression Analysis', Organizational Behavior and Human Decision Processes, 36(3), 305-323.

Farrell, D. and C. E. Rusbult (1981). 'Exchange Variables as Predictors of Job Satisfaction, Job Commitment, and Turnover: The Impact of Rewards, Costs, Alternatives, and Investments', Organizational Behavior and Human Performance, 28(1), 78-95.

Farth, J.-1., F. T. L. Leong and K. S. Law (1998). 'Cross-Cultural Validity of Holland's Model in Hong Kong', Journal of Vocational Behavior, 52(3), 425-440. 
Ferris, D. L., D. J. Brown and D. Heller (2009). 'Organizational Supports and Organizational Deviance: The Mediating Role of Organization-Based Self-Esteem', Organizational Behavior and Human Decision Processes, 108(2), 279-286.

Fornell, C. and D. F. Larcker (1981).'Evaluating Structural Equation Models with Unobservable Variables and Measurement Error', Journal of Marketing Research, 18(1), 39-50.

Frazier, L. M., P. D. Johnson, M. Gavin, J. Gooty and D. Bradley Snow (2010).

'Organizational Justice, Trustworthiness, and Trust: A Multifoci Examination', Group \& Organization Management, 35(1), 39-76.

Frenkel, S. J. and K. Sanders (2007). 'Explaining Variations in Co-worker Assistance in Organizations', Organization Studies, 28(6), 797-823.

Fuller, J. B., K. Hester, T. Barnett, L. Frey, C. Relyea and D. Beu (2006). 'Perceived External Prestige and Internal Respect: New Insights into the Organizational Identification Process', Human Relations, 59(6), 815-846.

Gibney, R. A. Y., T. J. Zagenczyk, J. B. Fuller, K. I. M. Hester and T. Caner (2010). 'Exploring Organizational Obstruction and the Expanded Model of Organizational Identification', Journal of Applied Social Psychology, 41(5), 1083-1109.

Goodfriend, W. and C. R. Agnew (2008). 'Sunken Costs and Desired Plans: Examining Different Types of Investments in Close Relationships', Personality and Social Psychology Bulletin, 34(12), 1639-1652.

Gundlach, M., S. Zivnuska and J. Stoner (2006). 'Understanding the Relationship Between Individualism-Collectivism and Team Performance Through an Integration of Social Identity Theory and the Social Relations Model', Human Relations, 59(12), 1603-1632. Hair, J. F., W. C. Black, B. J. Babin, R. E. Anderson and R. L. Tatham (2006). Multivariate Data Analysis. Prentice-Hall Inc, Upper Saddle River, New Jersey. 
Hekman, D. R., G. A. Bigley, H. K. Steensma and J. F. Hereford (2009). 'Combined effect of organizational identification and professional identification on the reciprocity dynamic for professional employees', Academy of Management Journal, 52(3), 506-526.

Hekman, D. R., H. K. Steensma, G. A. Bigley and J. F. Hereford (2009). 'Effects of Organizational and Professional Identification on the Relationship Between Administrators' Social Influence and Professional Employees' Adoption of New Work Behavior', Journal of Applied Psychology, 94(5), 1325-1335.

Hofstede, G. H. (2003). Culture's Consequences: Comparing Values, Behaviors, Institutions, and Organizations Across Nations. Sage Publications, Thousand Oaks.

Hogg, M. A. and D. J. Terry (2000). 'Social Identity and Self-Categorization Processes in Organizational Contexts', The Academy of Management Review, 25(1), 121-140.

Hogg, M. A. and D. J. Terry (2001). Social Identity Process in Organisational Contexts. Psychology Press, Philadelphia.

Hom, P. W., A. S. Tsui, J. B. Wu, T. W. Lee, A. Y. Zhang, P. P. Fu and L. Li (2009). 'Explaining Employment Relationships With Social Exchange and Job Embeddedness', Journal of Applied Psychology, 94(4), 277-297.

Hrebiniak, L. G. and J. A. Alutto (1972). 'Personal and Role-Related Factors in the Development of Organizational Commitment', Administrative Science Quarterly, 17(4), $555-573$.

Iacobucci, D., Saldanha, N., \& Deng, X. (2007). A meditation on mediation: Evidence that structural equations models perform better than regressions. Journal of Consumer Psychology, 17(2), 139-153.

Islam, G. and M. J. Zyphur (2009). 'Rituals in Organizations: A Review and Expansion of Current Theory', Group \& Organization Management, 34(1), 114-139. 
Kanter, R. M. (1968). 'Commitment and Social Organization: A Study of Commitment Mechanisms in Utopian Communities', American Sociological Review, 33(4), 499-517.

Kiewitz, C., S. L. D. Restubog, T. Zagenczyk and W. Hochwarter (2009). 'The Interactive Effects of Psychological Contract Breach and Organizational Politics on Perceived Organizational Support: Evidence from Two Longitudinal Studies', Journal of Management Studies, 46(5), 806-834.

Knight, C. and S. A. Haslam (2010). 'Your Place or Mine? Organizational Identification and Comfort as Mediators of Relationships Between the Managerial Control of Workspace and Employees' Satisfaction and Well-being', British Journal of Management, 21(3), 717-735.

Kreiner, G. E. and B. E. Ashforth (2004). 'Evidence toward an Expanded Model of Organizational Identification', Journal of Organizational Behavior, 25(1), 1-28.

Ladd, D. and R. A. Henry (2000). 'Helping Coworkers and Helping the Organization: The Role of Support Perceptions, Exchange Ideology, and Conscientiousness', Journal of Applied Social Psychology, 30(10), 2028-2049.

Le, B. and C. R. Agnew (2003). 'Commitment and Its Theorized Determinants: A MetaAnalysis of the Investment Model', Personal Relationships, 10(1), 37-57.

Lee, J. and R. Peccei (2007). 'Perceived Organizational Support and Affective Commitment: The Mediating Role of Organization-Based Self-Esteem in the Context of Job Insecurity', Journal of Organizational Behavior, 28(6), 661-685.

Mael, F. and B. E. Ashforth (1992). 'Alumni and Their Alma Mater: A Partial Test of the Reformulated Model of Organizational Identification', Journal of Organizational Behavior, 13(2), 103-123.

Masterson, S. S., K. Lewis, B. M. Goldman and M. S. Taylor (2000). 'Intergrating Justice and Social Exchange: The Differing Effects of Fair Procedures and Treatment on Work Relationships', Academy of Management Journal, 43(4), 738-748. 
Millward, L. J., S. A. Haslam and T. Postmes (2007). 'Putting Employees in Their Place: The Impact of Hot Desking on Organizational and Team Identification', Organization Science, 18(4), 547-559.

Millward, L. J. and T. Postmes (2010). 'Who We Are Affects How We Do: The Financial Benefits of Organizational Identification', British Journal of Management, 21(2), 327-339.

Molm, L. D. (2003). 'Theoretical Comparisons of Forms of Exchange', Sociological Theory, 21(1), 1-17.

Muthen, L. K. \& Muthen, B. O. (1998-2010). Mplus User's Guide (Fifth Edition)., Los Angeles, CA: Muthen \& Muthen. Netemeyer, R. G., W. O. Bearden and S. Sharma (2003). Scaling Procedures: Issues and Applications. Sage Publications, Newbury Park, CA. Nunnally, J. (1978). Psychometric Theory. MacGraw-Hill, New York.

Oliver, N. (1990). 'Rewards, Investments, Alternatives and Organizational Commitment: Empirical Evidence and Theoretical Development', Journal of Occupational Psychology, 63(1), 19-31.

Olkkonen, M.-E.and J. Lipponen (2006). 'Relationships Between Organizational Justice, Identification with Organization and Work Unit, and Group-Related Outcomes', Organizational Behavior \& Human Decision Processes, 100(2), 202-215.

Pierce, J. L. and D. G. Gardner (2004). 'Self-Esteem Within the Work and Organizational Context: A Review of the Organization-Based Self-Esteem Literature', Journal of Management, 30(5), 591-622.

Podsakoff, P. M., S. B. MacKenzie, J.-Y.Lee and N. P. Podsakoff (2003). 'Common Method Biases in Behavioral Research: A Critical Review of the Literature and Recommended Remedies', Journal of Applied Psychology, 88(5), 879-903.

Redman, T. and E. Snape (2005). 'Exchange Ideology and Member-Union Relationships: An Evaluation of Moderation Effects', Journal of Applied Psychology, 90(4), 765-773. 
Rhoades, L. and R. Eisenberger (2002). 'Perceived Organizational Support: A Review of the Literature', Journal of Applied Psychology, 87(4), 698-714.

Rhoades, L., R. Eisenberger and S. Armeli (2001). 'Affective Commitment of the Organization: The Contribution of Perceived Organizational Support', Journal of Applied Psychology, 86(5), 825-836.

Riketta, M. (2005). 'Organizational Identification: A Meta-Analysis', Journal of Vocational Behavior, 66(2), 358-384.

Rusbult, C. E. (1980). 'Commitment and satisfaction in romantic associations: A test of the investment model', Journal of Experimental Social Psychology, 16(2), 172-186.

Rusbult, C. E. (1983). 'A Longitudinal Test of the Investment Model: The Development (and Deterioration) of Satisfaction and Commitment in Heterosexual Involvements', Journal of Personality and Social Psychology, 45(1), 101-117.

Rusbult, C. E. and D. Farrell (1983). 'A Longitudinal Test of the Investment Model: The Impact on Job Satisfaction, Job Commitment, and Turnover of Variations in Rewards, Costs, Alternatives, and Investments', Journal of Applied Psychology, 68(3), 429-438.

Rusbult, C. E., D. Farrell, G. Rogers and A. G. Mainous III (1988). 'Impact of Exchange Variables on Exit, Voice, Loyalty, and Neglect: An Integrative Model of Responses to Declining Job Satisfaction', The Academy of Management Journal, 31(3), 599-627.

Rusbult, C. E. and J. M. Martz (1995). 'Remaining in an Abusive Relationship: An Investment Model Analysis of Nonvoluntary Dependence', Personality and Social Psychology Bulletin, 21(6), 558-571.

Rusbult, C. E., J. M. Martz and C. R. Agnew (1998). 'The Investment Model Scale: Measuring Commitment Level, Satisfaction Level, Quality of Alternatives, and Investment Size', Personal Relationships, 5(4), 357-387. 
Scott, B. A. and J. A. Colquitt (2007). 'Are Organizational Justice Effects Bounded by Individual Differences? An Examination of Equity Sensitivity, Exchange Ideology, and the Big Five', Group \& Organization Management, 32(3), 290-325.

Settoon, R. P., N. Bennett and R. C. Liden (1996). 'Social Exchange in Organizations: Perceived Organizational Support, Leader -- Member Exchange, and Employee Reciprocity', Journal of Applied Psychology, 81(3), 219-227.

Siemsen, E., A. Roth and P. Oliveira (2010). 'Common Method Bias in Regression Models With Linear, Quadratic, and Interaction Effects', Organizational Research Methods, 13(3), 456-476.

Sluss, D. M., M. Klimchak and J. J. Holmes (2008). 'Perceived Organizational Support as a Mediator Between Relational Exchange and Organizational Identification', Journal of Vocational Behavior, 73(3), 457-464.

Smith, L. G. E., C. E. Amiot, V. J. Callan, D. J. Terry and J. R. Smith (2010). 'Getting New Staff to Stay: The Mediating Role of Organizational Identification', British Journal of Management, 23(1), 45-64.

Snape, E. and T. Redman (2010). 'HRM Practices, Organizational Citizenship Behaviour, and Performance: A Multi-Level Analysis', Journal of Management Studies, 47(7), 1219-1247.

Song, J. L., A. S. Tsui and K. S. Law (2009). 'Unpacking Employee Responses to Organizational Exchange Mechanisms: The Role of Social and Economic Exchange Perceptions \{dagger \}', Journal of Management, 35(1), 56-93.

Sperber, A. D., R. F. Devellis and B. Boehlecke (1994). 'Cross-Cultural Translation: Methodology and Validation', Journal of Cross-Cultural Psychology, 25(4), 501-524. Sturges, J., N. Conway and A. Liefooghe (2010). 'Organizational Support, Individual Attributes, and the Practice of Career Self-Management Behavior', Group \& Organization Management, 35(1), 108-141. 
Swain, S., D. Weathers and R. Niedrich (2008). 'Assessing Three Sources of Misresponse to Reversed Likert Items', Journal of Marketing Research, 45(1), 116-131.

Tajfel, H. (1978). 'Social Categorization, Social Identity, and Social Comparison'. In: H. Tajfel (Ed.) Differentiation Between Social Groups. Academic Press, New York.

Tajfel, H. and J. C. Turner (1985). 'The Social Identity Theory of Intergroup Behavior'. In: S. Worchel and W. G. Austin (Eds.), Psychology of Intergroup Relations. Nelson-Hall, Chicago..

Takeuchi, R., S. Yun and K. F. E. Wong (2011). 'Social Influence of a Coworker: A Test of the Effect of Employee and Coworker Exchange Ideologies on Employees' Exchange Qualities', Organizational Behavior and Human Decision Processes, 115(2), 226-237.

Tan, H. H. and D. Chee (2005). 'Understanding Interpersonal Trust in a Confucian-Influenced Society', International Journal of Cross Cultural Management, 5(2), 197-212.

Tangirala, S., S. G. Green and R. Ramanujam (2007). 'In the Shadow of the Boss's Boss: Effects of Supervisors' Upward Exchange Relationships on Employees', Journal of Applied Psychology, 92(2), 309-320.

Tekleab, A. G., R. Takeuchi and M. S. Taylor (2005). 'Extending the Chain of Relationships among Organizational Justice, Social Exchange, and Employee Reactions: The Role of Contract Violation', Academy of Management Journal, 48(1), 146-157.

Turner, J. C., M. A. Hogg, P. J. Oakes, S. D. Reicher and M. S. Wetherell (1987). Rediscovering the Social Group: A Self Categorization Theory. Blackwell, Oxford. Tyler, T. R. (1999). 'Why People Cooperate with Organizations: An Identity-Based Perspective'. In: R. I. Sutton and B. M. Staw (Ed.), Research in Organizational Behavior. JAI Press, Stamford, Connecticut. 
Tyler, T. R. and S. L. Blader (2003). 'The Group Engagement Model: Procedural Justice, Social Identity, and Cooperative Behavior', Personality and Social Psychology Review, 7(4), 349-361.

Van Dick, R., O. Christ, J. Stellmacher, U. Wagner and e. al (2004). 'Should I Stay or Should I Go? Explaining Turnover Intentions with Organizational Identification and Job Satisfaction', British Journal of Management, 15(4), 351-360.

Van Dick, R., M. W. Grojean, O. Christ and J. Wieseke (2006). 'Identity and the Extra Mile: Relationships Between Organizational Identification and Organizational Citizenship Behaviour', British Journal of Management, 17(4), 283-301.

Van Knippenberg, D., R. van Dick and S. Tavares (2007). 'Social Identity and Social Exchange: Identification, Support, and Withdrawal From the Job', Journal of Applied Social Psychology, 37(3), 457-477.

Walumbwa, F. O., B. J. Avolio and W. Zhu (2008). 'How Transformational Leadership Weaves Its Influence on Individual Job Performance: The Role of Identification and Efficacy Beliefs', Personnel Psychology, 61(4), 793-825.

Walumbwa, F. O., D. M. Mayer, P. Wang, H. Wang, K. Workman and A. L. Christensen (2011). 'Linking Ethical Leadership to Employee Performance: The Roles of LeaderMember Exchange, Self-Efficacy, and Organizational Identification', Organizational Behavior and Human Decision Processes, 115(2), 204-213.

Wang, P. and J. C. Rode (2010). 'Transformational Leadership and Follower Creativity: The Moderating Effects of Identification With Leader and Organizational Climate', Human Relations, 63(8), 1105-1128.

Wayne, S. J., L. M. Shore and R. C. Liden (1997). 'Perceived Organizational Support and Leader-Member Exchange: A Social Exchange Perspective', Academy of Management Journal, 40(1), 82-111. 
Wiesenfeld, B., S. Raghuram and R. Garud (2001). 'Organizational Identification Among Virtual Workers: The Role of Need for Affiliation and Perceived Work-Based Social Support', Journal of Management, 27(2), 213-229.

Witt, L. A. and D. Broach (1993). 'Exchange Ideology as a Moderator of the Procedural Justice-Satisfaction Relationship', Journal of Social Psychology, 133(1), 97-103.

Witt, L. A., K. M. Kacmar and M. C. Andrews (2001). 'The Interactive Effects of Procedural Justice and Exchange Ideology on Supervisor-Rated Commitment', Journal of Organizational Behavior, 22(5), 505-515.

Witt, L. L. (1992). 'Exchange Ideology as a Moderator of the Relationships Between Importance of Participation in Decision Making and Job Attitudes', Human Relations, 45(1), 73-85.

Zagenczyk, T. J., K. D. Scott, R. Gibney, A. J. Murrell and J. B. Thatcher (2010). 'Social Influence and Perceived Organizational Support: A Social Networks Analysis', Organizational Behavior and Human Decision Processes, 111(2), 127-138. 
Appendix A: Measurement Model Testing

\begin{tabular}{|c|c|c|c|c|c|c|c|}
\hline Structure & $\chi^{2}$ & df & $\chi^{2} / \mathbf{d f}$ & CFI & RMSEA & $\Delta \chi^{2 \mathrm{a}}$ & $\Delta \chi^{2} / \mathbf{d f}^{\mathrm{a}}$ \\
\hline Model 1: Four-factor model & 526.288 & 146 & 3.605 & .92 & .072 & & \\
\hline Model 2: Three-factor combining OID and EXID & 1185.046 & 149 & 7.953 & .78 & .118 & 658.758 & 219.586 \\
\hline Model 3: Three -factor combining OID and POS & 1278.476 & 149 & 8.580 & .76 & .123 & 752.188 & 250.729 \\
\hline Model 4: Three -factor combining OID and EMIN & 803.124 & 149 & 5.390 & .86 & .094 & 276.836 & 92.279 \\
\hline Model 5: Three -factor combining EXID and POS & 1259.176 & 149 & 8.451 & .77 & .122 & 732.888 & 244.296 \\
\hline Model 6: Three -factor combining EXID and EMIN & 996.262 & 149 & 6.686 & .82 & .107 & 469.974 & 156.658 \\
\hline Model 7: Three -factor combining POS and EMIN & 843.332 & 149 & 5.660 & .86 & .096 & 317.044 & 105.681 \\
\hline Model 8: One-factor model & 2239.997 & 152 & 14.737 & .57 & .166 & 1713.709 & 571.236 \\
\hline
\end{tabular}

Note: OID = Organizational iden

2239.997

$152-14.737$

.166 1713.709

571.236

${ }^{\mathrm{a}} \chi^{2}$ tests relative to model 1 . 

Figure 1: Conceptual Framework and Hypotheses

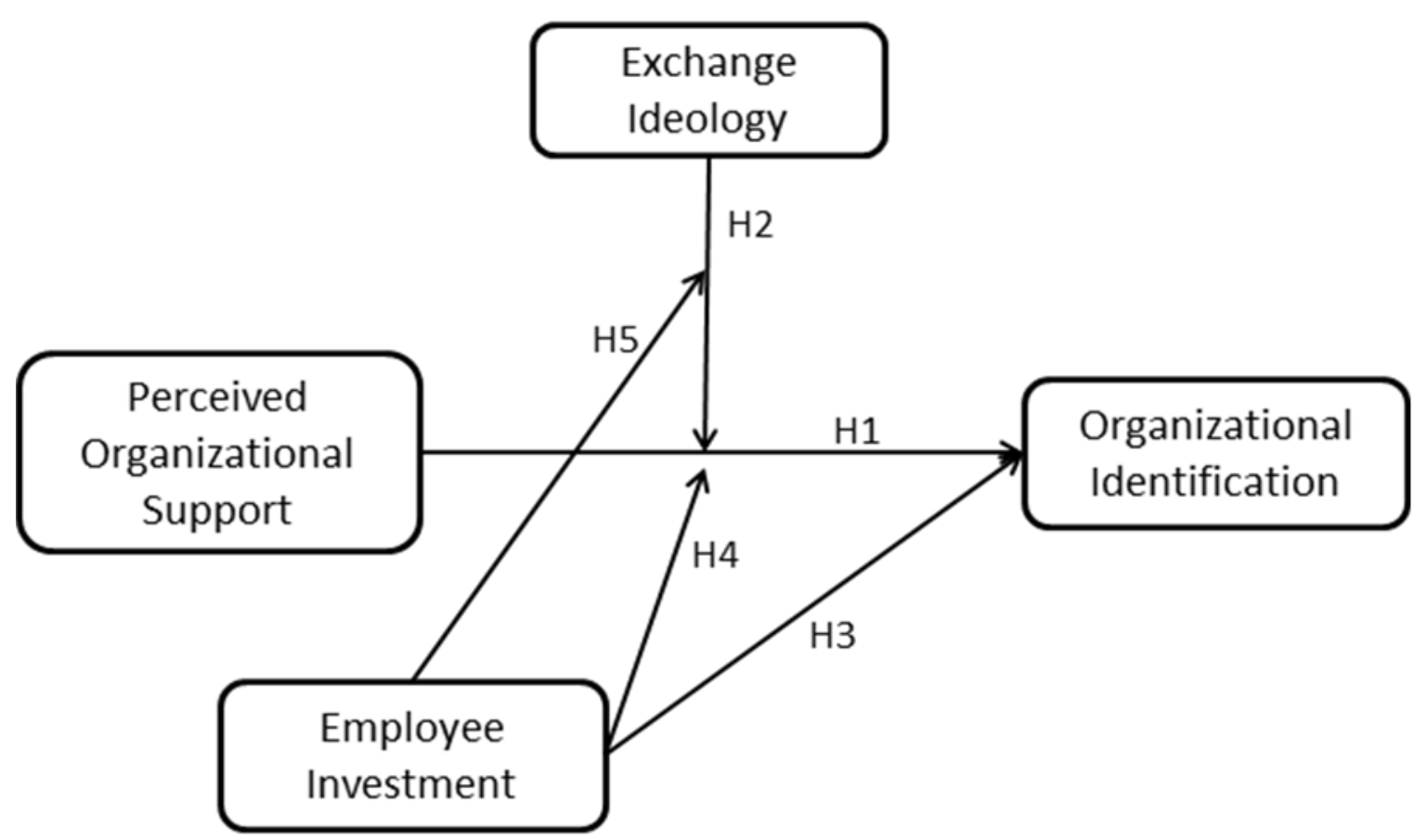


Figure 2: The Moderating Effect of Exchange Ideology (EXID) on POS

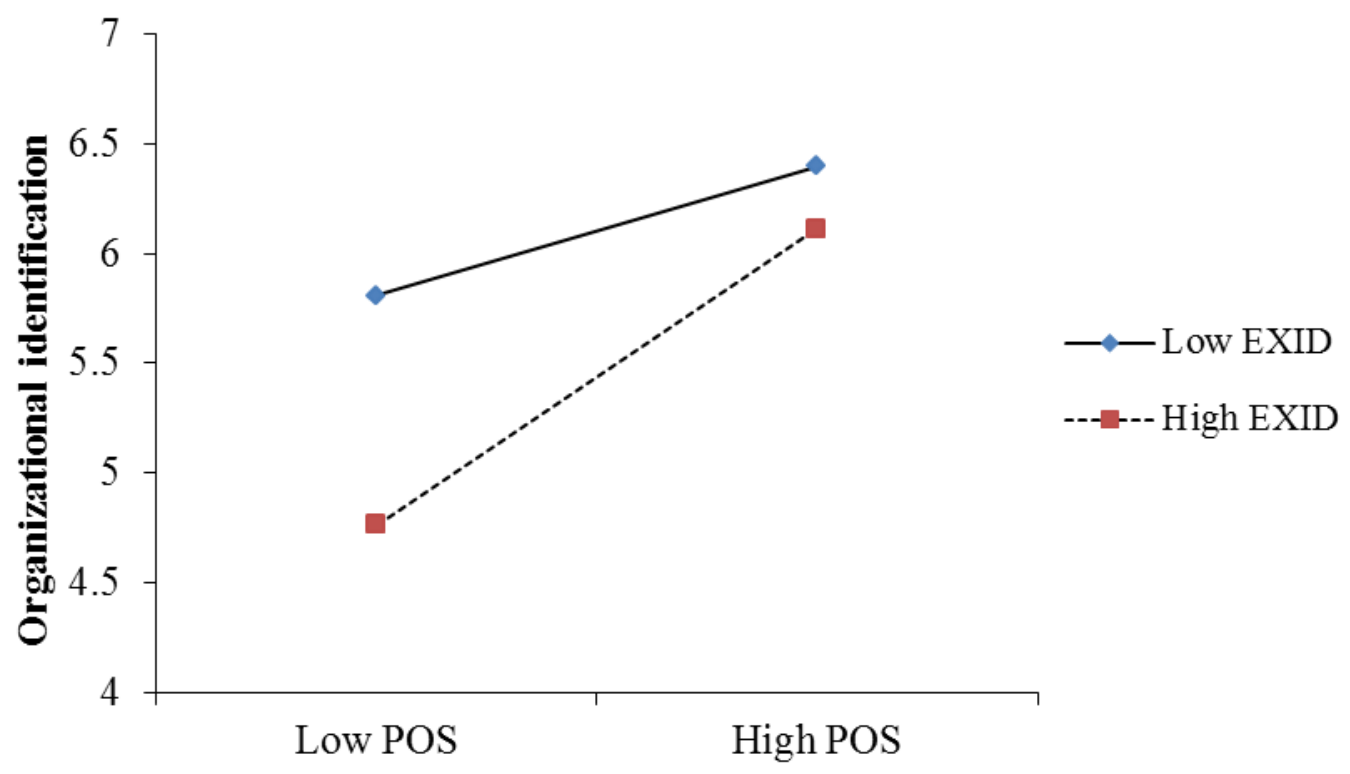


Figure 3: Moderating Effect of Employee Investment (EPIN) on the Effect of POS on OID

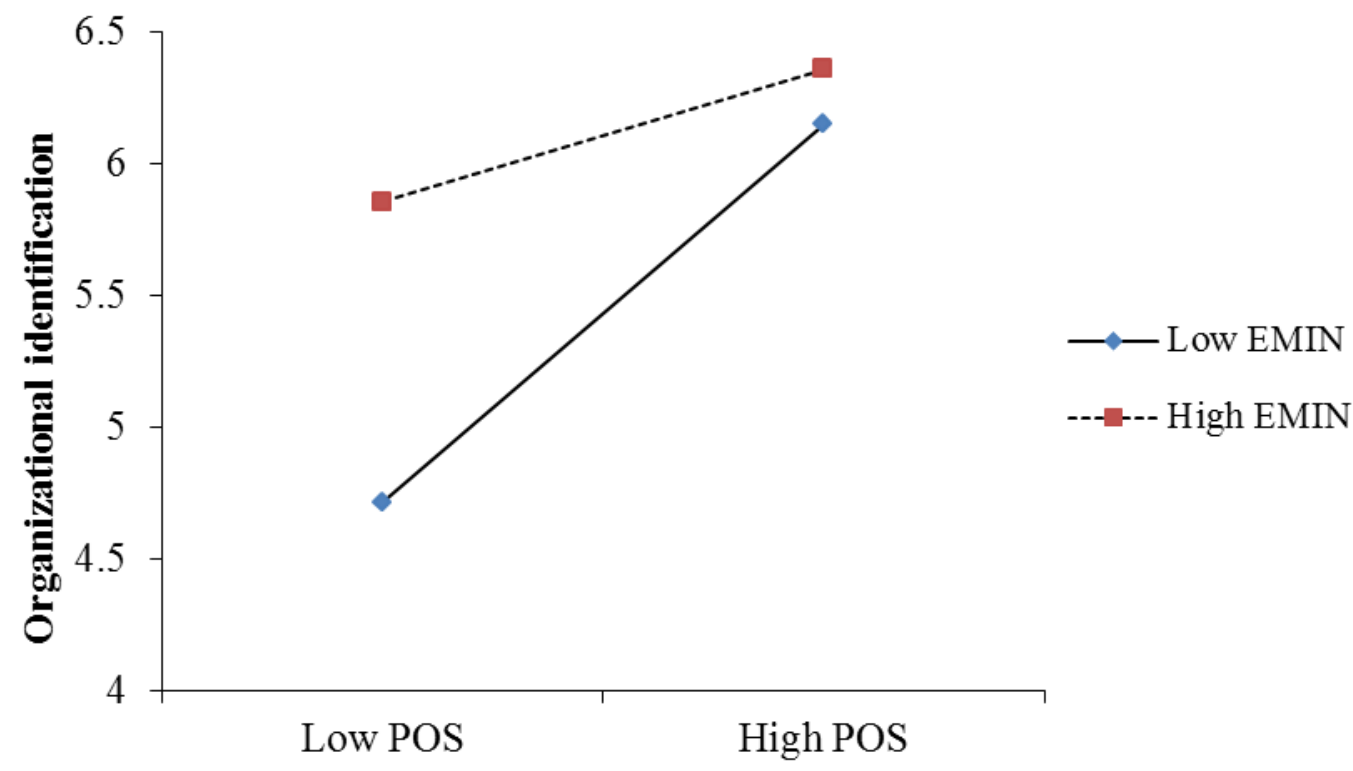


Figure 4: Joint Moderating Effect of Exchange Ideology (EXID) and Employee Investment (EPIN) on the Effect of POS on OID

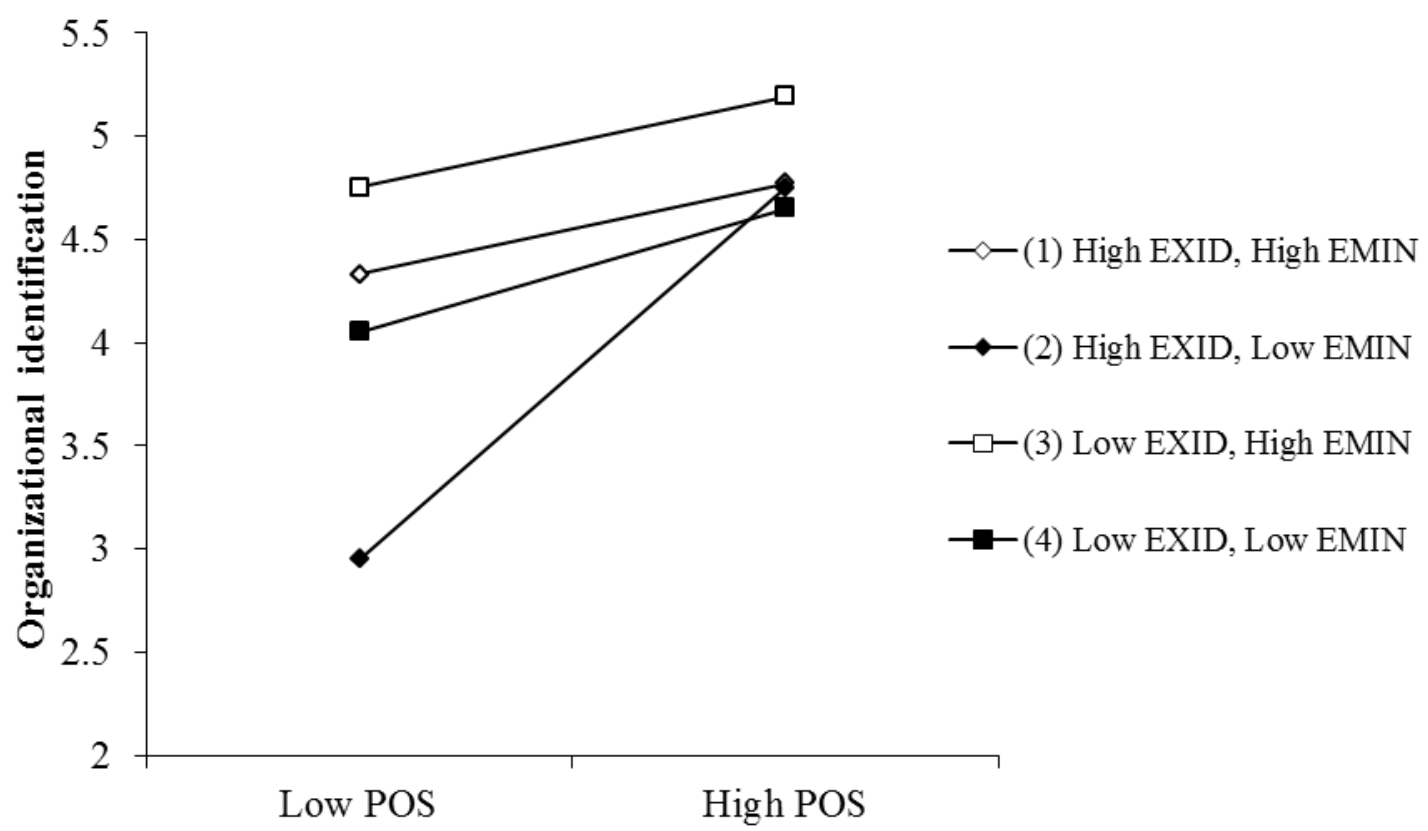

Note: Slope 2 (when exchange ideology is high and employee investment is low) is significantly different from all other three slopes ( $p<.001$ in all cases). There is no significant difference among the other three slopes. 
Table 1: Measurement Items and Factor Analyses Results

\begin{tabular}{|c|c|c|}
\hline \multirow{2}{*}{ Items } & \multicolumn{2}{|c|}{ Factor loading } \\
\hline & CFA & EFA \\
\hline Organizational identification (OID) & & $18.29 \%^{a}$ \\
\hline When someone criticize X, I feels like a personal insult. & .80 & .78 \\
\hline I am very interested in what others think about $X$. & .84 & .81 \\
\hline When I talk about X, I usually say "we" rather than "they". & .67 & .76 \\
\hline When someone praises X, I feels like a personal compliment. & .70 & .69 \\
\hline If a story in the media criticized X, I would feel embarrassed. & .79 & $\begin{array}{c}.75 \\
21.96 \%\end{array}$ \\
\hline Perceive organizational support (POS) & & \\
\hline $\mathrm{X}$ takes pride in my accomplishments. & .70 & .64 \\
\hline $\mathrm{X}$ really cares about my well-being. & .77 & .78 \\
\hline $\mathrm{X}$ values my contributions to its well-being. & .84 & .82 \\
\hline $\mathrm{X}$ strongly considers my goals and values. & .84 & .86 \\
\hline $\mathrm{X}$ shows high concern for me. & .86 & .85 \\
\hline $\mathrm{X}$ is willing to help me if I need a special favour. & .78 & $\begin{array}{c}.81 \\
10.75 \%\end{array}$ \\
\hline Employee investment (EMIN) & & \\
\hline In general, how much have you invested in your present job at $\mathrm{X}$ ? & .84 & .81 \\
\hline $\begin{array}{l}\text { All things considered, are there issues uniquely associated with your present job at } \mathrm{X} \text { that } \\
\text { you would lose if you were to leave your present job? }\end{array}$ & .58 & .68 \\
\hline $\begin{array}{l}\text { How does your investment in your present job at X compare to what you think most people } \\
\text { have invested in their jobs? }\end{array}$ & .71 & .85 \\
\hline Exchange Ideology (EXID) & & $15.25 \%$ \\
\hline Employees should not care about $\mathrm{X}$ unless $\mathrm{X}$ shows that it cares about its employees. & .74 & .73 \\
\hline Employees should only go out of their way to help X if it goes out of its way to help them. & .74 & .73 \\
\hline An employee who is treated badly by $\mathrm{X}$ should work less hard. & 68 & .77 \\
\hline $\begin{array}{l}\text { An employee's work effort should depend partly on how well } \mathrm{X} \text { deals with his or her desires } \\
\text { and concerns. }\end{array}$ & .62 & .77 \\
\hline $\begin{array}{l}\text { An employee should only work hard if his or her efforts will lead to a pay increase, } \\
\text { promotion, or other benefits. }\end{array}$ & 63 & .76 \\
\hline
\end{tabular}

Note: CFA = Confirmatory Factor Analysis; EFA = Exploratory Factor Analysis.

${ }^{a}$ Percentage of variance extracted by EFA with Varimax rotation. There is no cross-factor loading higher than .50 . 
Table 2: Descriptive Statistics of Variables

\begin{tabular}{lccccccc}
\hline & 1 & 2 & 3 & 4 & 5 & 6 & 7 \\
\hline 1.Organizational identification & .76 & & & & & & \\
2.Sex & -.05 & - & & & & & \\
3.Management & -.08 & .05 & - & & & & \\
4.Age & .04 & $.15^{* *}$ & $.38^{* *}$ & - & & & \\
5.Perceived org. support & $.52^{* *}$ & .08 & .06 & .04 & .79 & & \\
6.Employee investment & $.40^{* *}$ & -.03 & $.10^{*}$ & .05 & $.36^{* *}$ & .71 & \\
7.Exchange ideology & $-.24^{* *}$ & -.01 & $.12^{* *}$ & .01 & $-.17^{* *}$ & -.00 & .69 \\
& & & & & & & \\
Mean & 5.66 & - & - & 31.61 & 4.72 & 4.86 & 4.04 \\
S.D. & 1.08 & - & - & 5.50 & 1.24 & .99 & 1.28 \\
AVE & .57 & - & - & - & .63 & .51 & .47 \\
CR & .88 & - & - & - & .91 & .74 & .81 \\
Cronbach Alpha & .87 & - & - & - & .91 & .74 & .77 \\
\hline
\end{tabular}

$* p<.05 ; * * p<.01$. Diagonal represents square root of AVE score. AVE= Average Variance Extracted; CR = Composite Reliability; S.D. = Standard Deviation; Perceived org. support $=$ Perceived organizational support. Dummy variable coding: Sex $(1=$ Male; $0=$ Female $)$; Management $(1=$ With supervisory role; $0=$ Without supervisory role). 
Table 3: Results of Moderated Structural Equation Modelling

\begin{tabular}{lccc}
\hline & Model 1 & Model 2 & Model 3 \\
\hline Sex & -.04 & -.03 & .03 \\
Management level & -.05 & -.07 & -.06 \\
Age & -.02 & .01 & -.03 \\
POS & $.40^{* *}$ & $.39^{* *}$ & $.41^{* *}$ \\
EMIN & $.35^{* *}$ & $.34^{* *}$ & $.33^{* *}$ \\
EXID & $-.23^{* *}$ & $-.26^{* *}$ & $-.22^{* *}$ \\
& & & \\
Two-way interactions & & & $.15^{* *}$ \\
EXID $\times$ POS & & $-.19^{* *}$ & $-.19^{* *}$ \\
ORIN $\times$ POS & & .02 & .02 \\
EXID $\times$ EMIN & & & \\
& & & $-.15^{* *}$ \\
Three-way interaction & & & .55 \\
EXID $\times$ EMIN $\times$ POS & & .54 & .01 \\
$\mathrm{R}^{2}$ & .50 & .04 & \\
$\Delta \mathrm{R}^{2}$ & & & \\
\hline
\end{tabular}

Dependent variable: Organizational identification. Dummy variable coding: Sex $(1=$ Male; $0=$ Female $)$; Management level $(1=$ With supervisory role; $0=$ Without supervisory role $)$. POS $=$ Perceived organizational support; EMIN = Employee investment; EXID = Exchange ideology.

$* * p<.01$ 